\title{
Mobile phone text messaging to reduce alcohol and tobacco use in young people - a narrative review
}

\section{Severin Haug}

Swiss Research Institute for Public Health and Addiction at Zurich University, Zurich, Switzerland
Correspondence: Severin Haug Swiss Research Institute for Public Health and Addiction, Konradstrasse 32,

PO Box, 803। Zurich, Switzerland $\mathrm{Tel}+4 \mid 44448$ I I 74

Fax +4I 44448 II 70

Email severin.haug@isgf.uzh.ch
This article was published in the following Dove Press journal:

Smart Homecare Technology and TeleHealth

23 October 2013

Number of times this article has been viewed

Background: Alcohol and tobacco use are major causes of the disease burden in most countries of the world. Mobile phone text messaging is very popular among adolescents and young adults and has the potential to deliver individualized information to large population groups at low costs.

Objective: To provide a narrative review on studies testing the appropriateness and effectiveness of text messaging-based programs to reduce alcohol and tobacco use in young people.

Results: Two published studies on text message-based programs for the reduction of problem drinking and two studies on programs for enhancing smoking cessation were identified. A US-American pilot experimental study tested the feasibility and initial efficacy of a text messaging-based assessment and brief intervention among young adults identified during their emergency department visit with hazardous drinking. It demonstrated the feasibility of the text messaging-based program to collect drinking data in young adults after emergency department discharge. A Swiss pre-post study tested the appropriateness and initial effectiveness of a combined, individually tailored web- and text messaging (SMS)-based program to reduce problem drinking in vocational school students. It provided evidence for the appropriateness of the intervention and initial evidence for its efficacy to reduce problem drinking. One of the two studies addressing smoking cessation was a US-American pilot randomized controlled trial. Participants were recruited via online advertisements and received text messages tailored according to their quitting stage. The intervention significantly affected self-reported quitting rates at 4 weeks but not at 3 months after the quit date. Within a cluster-randomized controlled trial conducted in Switzerland, smoking students were proactively recruited within vocational school classes and received text messages tailored to demographic and smoking-related variables. The program was accepted very well by the target group. It did not affect smoking abstinence rates at 6-months follow-up but resulted in significant lower cigarette consumption.

Conclusion: First results on the appropriateness and short-term efficacy of text message-based interventions to reduce tobacco and alcohol use in young people are promising; however, further adequately powered trials are needed to confirm these initial results and to test the longer-term efficacy of these programs.

Keywords: text messaging, alcohol, tobacco, young people

\section{Background}

\section{Problem drinking and tobacco smoking in young people}

Alcohol and tobacco use are major causes of the disease burden in most countries of the world. ${ }^{1}$ In adolescents and young adults of developed countries, alcohol use constitutes the greatest risk factor for mortality and morbidity. ${ }^{2}$ In Europe, alcohol is responsible for $12 \%$ of male and $2 \%$ of female premature death and disability. ${ }^{3}$ 
Problem drinking is associated with multiple social and interpersonal problems such as arguing with friends and parents, engaging in unplanned sexual activity, drinking and driving, assault, getting into trouble with the law, academic difficulties, unintended injuries, and suicidal acts. In the long term, problem drinkers have an elevated risk of developing chronic diseases, eg, heart and liver diseases or alcohol dependence. ${ }^{3-7}$ Indicators of problem drinking are a) a daily average consumption of three or more standard drinks for men, and two or more for women ${ }^{8}$ and b) risky, single-occasion drinking (RSOD, also called binge drinking), defined as drinking five or more drinks on an occasion for men and four or more drinks for women. ${ }^{9}$ The prevalence rates of RSOD are particularly high in adolescence and young adulthood, and are higher among men than among women. ${ }^{10}$ Based on data from 15-16-year-old European students, 39\% reported having had five drinks or more on the same occasion during the past 30 days, and 14\% indicated that this had happened at least three times during the period in question. ${ }^{11}$

Cigarette smoking, the most common form of nicotine use, is the single most preventable cause of death in the world and continues to be a serious problem. ${ }^{1}$ Cigarette smoking is most often initiated during adolescence. Adolescent smoking raises the risk for adult smoking by a factor of 16 compared to nonsmoking adolescents. ${ }^{12}$ It results in health consequences already during adolescence and negative effects on the developing brain. ${ }^{13}$ A survey of 15- and 16-year-old adolescents covering 36 European countries revealed that the smoking prevalence rate of $28 \%$ having used cigarettes during the past 30 days has remained stable over the last 4 years. ${ }^{11}$ Smoking prevalences are particularly high in adolescents and young adults with lower educational levels. ${ }^{14}$

\section{Interventions to reduce problem drinking and tobacco smoking in young people}

Studies testing the efficacy of interventions to reduce problem drinking among adolescents were predominantly conducted in college or university students. ${ }^{15}$ Within this target group, individual interventions using motivational interviewing ${ }^{16}$ or personalized normative feedback based on the social norms approach ${ }^{17}$ were effective to reduce alcohol consumption and alcohol-related problems. ${ }^{18}$ While interventions based on motivational interviewing are typically provided in face-to-face counseling sessions, social norms interventions were mostly provided via tailored letters generated by a computer. This intervention approach is promising to deliver individualized interventions to large audiences with minimal personal effort.
There is limited evidence of efficacy for smoking cessation interventions in young people. ${ }^{19,20}$ The 2006 Cochrane Review for smoking cessation interventions for persons younger than 20 years identified 15 trials of sufficient quality, of which only one ${ }^{21}$ found statistically significant evidence of an intervention effect. ${ }^{19}$ The authors acknowledged that there is a need for well-designed, adequately powered trials of cessation interventions. They concluded that complex approaches, including elements sensitive to the stage of change, achieved moderate long-term success, whereas the efficacy of psychosocial and pharmacological interventions could not be demonstrated. A more recent but less systematic review from $2008^{20}$ suggested that delivering smoking cessation programs for youth in contexts that are geared to youth, interventions addressing cognitive-behavioral, motivational, and social influence contents, and programs with at least five sessions were most effective.

Beyond intervention effectiveness, intervention reach and retention are major challenges of smoking cessation interventions in young people. ${ }^{22,23}$ Reaching a large proportion of adolescent smokers has been difficult. However, a large reach is essential for the efficacy of an intervention at the population level. For a large reach, proactive recruitment strategies are needed that address all persons among a given target population. All smokers should receive the invitation to take part in smoking cessation. Such recruitment, in combination with low-threshold interventions, seems promising. ${ }^{24,25}$

\section{Computer-tailored interventions}

Computer-tailored interventions for health behavior change are typically based on expert systems. These systems automatically generate information to support behavior change based on individual characteristics. They provide a viable, time- and cost-saving alternative to interpersonal counseling. ${ }^{26}$ Individually tailored messages, related to the outcome of interest and derived from an individual assessment, proved to be more effective than generic messages or messages which were targeted to a specific segment of the population only. ${ }^{27}$ Studies in which intervention materials were individually tailored on a) a theoretical concept, b) current behavior, and c) demographic variables showed the highest effectiveness, whereas interventions tailored on one or two of these characteristics only were less effective. Although the exact mechanism responsible for this tailoring effect is not known, it is generally believed that compared to untailored messages, tailored messages are more likely to be attended to. ${ }^{28,29}$ 
In a recent study, the published literature on Internet and mobile phone interventions to decrease alcohol consumption in adolescents and young adults was reviewed. ${ }^{30}$ This review included 19 articles addressing the efficacy of web-based interventions to decrease alcohol consumption. Sixteen out of the 19 studies were conducted in college or university students from the United States or New Zealand, and the majority of these studies were based on the social norms approach. ${ }^{30}$ This approach hypothesizes that the presentation of correct information about peer group drinking norms in a credible way reduces peer pressure for high levels of alcohol consumption in both problem drinkers and nondrinkers. The feedback provides comparisons between the actual drinking norm and perceptions of the norm as well as a personal drinking profile, including quantity of alcohol consumed in relation to peers, money spent on alcohol, calorie intake, and individual risk patterns of alcohol-related negative consequences. The effectiveness of social norms interventions to reduce alcohol misuse in university and college students was analyzed in a Cochrane review. ${ }^{31}$ This review concluded that the efficacy of social norm marketing campaigns and group feedback is questionable; however, normative feedback interventions delivered using the web or computer reduced drinking quantity, drinking frequency, and binge drinking in the short- and medium-term.

\section{Interventions delivered by mobile phone short message service}

Mobile phone text messaging is very popular among adolescents and young adults, and has the potential to deliver individualized information and support to large proportions of the population. It provides an opportunity for individualized and interactive information delivery that may easily be accessed, independent of time and place. In Switzerland, as in most other developed countries, nearly all adolescents $(95 \%)$ between the ages of 12 and 19 own a mobile phone, and text messaging is the most commonly used mobile phone application. $^{32}$

Mobile phone text messaging is increasingly applied in the context of behavior change interventions, particularly for smoking cessation and diabetes self-management. ${ }^{33,34}$ A recent Cochrane Review including five randomized or quasi-randomized studies revealed an overall long-term benefit of mobile phone interventions for smoking cessation in adults, ${ }^{33}$ although there was a high level of statistical heterogeneity in the pooled results. A large methodologically sound trial was conducted in Great Britain to test the efficacy of SMS-based smoking cessation interventions in adults motivated to quit smoking. ${ }^{35}$ Within this study, smokers who intended to quit within the subsequent month received motivational messages and behavioral-change support over a period of 26 weeks. The messages were matched to participants' demographic and smoking-related characteristics gathered at baseline. Additionally, participants could request instant messages within craving or lapse situations. The program significantly improved smoking cessation rates at 6-month follow-up compared to a control group that received text messages unrelated to quitting (9\% versus $4 \%$, respectively).

Text messaging is also promising for the enhancement of interventions to reduce problem drinking in young people. The promising and frequently used social norm interventions typically consist of a single intervention session in which participants receive tailored web or printed feedback. Due to their length of up to 7-8 pages of text and graphics, this type of feedback is primarily suited for individuals who are motivated and able to process this information. To provide shorter but more recurrent feedback messages might be a more effective approach, particularly for individuals with lower educational levels, but also to support and maintain behavior change over a longer time period. Text messaging provides a suitable technology to deliver short and repeated feedback messages and allows the delivery of individualized messages at times when young people typically drink alcohol. ${ }^{36}$

\section{Objectives}

This paper aims to provide a narrative review on studies testing the appropriateness and effectiveness of text messaging-based programs to reduce alcohol and tobacco use in young people. Electronic searches of PubMed, MEDLINE, Web of Science, and the Cochrane Register of Controlled Trials were conducted in August 2013. Studies, published in scientific journals, containing English abstracts, and reporting results about the efficacy or appropriateness of text messaging-based programs to reduce alcohol or tobacco use in young people were included in the review.

\section{Studies on text messaging-based programs to reduce alcohol and tobacco use in young people Studies on programs for the reduction of alcohol use}

In August 2013, two published studies on text messagingbased programs for the reduction of alcohol use in young 
people were available. The Pittsburgh Alcohol Reduction through Text-Messaging (PART) study was conducted in the US in 2010/11 $1^{37}$ and the study testing the program Alk-Check was conducted in Switzerland in 2012/13. ${ }^{38}$

\section{PART}

The PART study ${ }^{37}$ was a pilot experimental study testing the feasibility and initial efficacy of a text messaging-based assessment and brief intervention among young adults identified during their emergency department visit with hazardous drinking. During a period of 24 days, a total of 45 young adults aged 18-24 years who owned a personal mobile phone with text messaging features were identified as hazardous drinkers. They were randomly assigned to a) an assessment group, b) an intervention group, or c) a control group.

Within the assessment group, participants received two text message questions per week. The first question assessed the number of drinking days in the last week, the second question the maximum number of drinks over a 24-hour period in the last week. Within the intervention group, participants also received the weekly text message questions. Additionally, they received automated responses contingent on their answers. Participants who replied that they had not consumed any drinks were motivated to maintain their drinking behavior. Men who reported $<5$ and women who reported $<4$ drinks in any one 24 -hour period in the last week received a message with education about the dangers of alcohol. Participants with a higher number of drinks in any one 24-hour period in the last week were asked whether they would set a goal to reduce their drinking. Participants indicating 'yes' were provided with reinforcement and strategies for cutting down. Participants indicating 'no' received a message encouraging them to reflect on their decision.

Participants of all groups received $\$ 20$ for completion of the baseline assessment and $\$ 40$ for completion of the follow-up assessments. Additionally, participants in the assessment and intervention groups received $\$ 30$ if they replied to at least 10 of the 12 weekly text message questions.

Among the participants in the assessment and intervention groups, 95\% replied to the weekly text messaging queries at least once; $73 \%$ of the participants in the assessment group and $80 \%$ in the intervention group completed all 12 weeks of queries.

The exploration of drinking outcomes showed that within the intervention group, the number of heavy drinking days in the last month and drinks per drinking day decreased from baseline to follow-up. In contrast, participants of the assessment group increased their drinking over the course of the study. A significant difference on the change in heavy drinking days and drinks per drinking day was observed between the intervention group and the assessment group.

Overall, the findings of the PART study demonstrate the feasibility of a text messaging-based program to collect drinking data in young adults after emergency department discharge over a 12-week period. However, participant payments may have increased participation rate and rate of replies to the weekly text messaging queries. Due to the small sample size, the study does not allow sound conclusions to be drawn regarding the efficacy of the intervention approach.

\section{Alk-Check}

A longitudinal, pre-post study design was used to test the appropriateness and initial effectiveness of a combined, individually tailored web- and text messaging (SMS)based intervention program to reduce problem drinking in vocational school students. ${ }^{38}$ The fully automated program provided a) online feedback about an individual's drinking pattern compared to the drinking norms of an age- and sexspecific reference group and b) recurrent individualized SMS messages over a time period of 3 months.

Study participants were recruited in 36 vocational school classes. All students who owned a mobile phone were invited for study participation irrespective of their alcohol consumption. Of the 477 persons who owned a mobile phone, 364 (76.3\%) registered for program participation.

The interventional content was based on social norms intervention programs. The program automatically generated individually tailored online feedback and SMS messages using data from a comprehensive online assessment of demographic data, alcohol consumption, drinking behavior (eg, typical drinking days and times), and alcohol-related problems. After completing the online assessment, individually tailored online feedback was provided. It included graphical and textual information concerning a) drinks per week in relation to the age and sex-specific reference group, b) financial costs of drinking, c) calories consumed with alcoholic drinks, and d) number of heavy drinking occasions in relation to the age and sex-specific reference group.

The content and number of the provided text messages were tailored according to baseline drinking patterns. Participants were assigned to one of three risk groups (nonrisk, low-risk, high-risk) based on their baseline drinking patterns.

On the second level, the content of the text messages was tailored according to the individual values on the following baseline variables: sex, motivation for reduced alcohol 
consumption, alcohol-related problems, typical drinking day and time, number of standard drinks in a typical week, and maximum number of drinks on a single occasion during the last 30 days.

Participants from all risk groups received text messages for a period of 12 weeks. Participants of the non-risk group received one weekly text message providing information from the following content categories: a) drinking and body weight/fitness, b) resisting peer pressure, c) pros of sensible drinking, and d) motivation to maintain sensible drinking.

Participants of the low-risk group received one weekly text message providing information from the following content categories: $(a-c)$, e) motivation for sensible drinking, f) alcohol-related problems, g) maximum number of drinks on a single occasion and related risks, h) risks of binge drinking, and i) importance of reducing alcohol consumption. Additionally, they received bi-weekly text messages sent on the individually indicated typical drinking day and time. The latter messages particularly focused on strategies to reduce alcohol consumption and to motivate them toward sensible drinking practices. Participants of the high-risk group received one weekly text message providing information from the content categories: $(\mathrm{a}-\mathrm{c}),(\mathrm{e}-\mathrm{i})$, and j) local outpatient services for alcohol counseling. They also received the additional bi-weekly text messages sent on the individually indicated typical drinking day and time. Sample text messages are shown in Table 1.

The overall acceptance of the intervention was good. Nearly all program participants (94\%) stayed logged in until the end of the program, which lasted 3 months. The SMS messages were read by almost all program participants (94\%), and both the SMS messages and the online feedback were comprehensible for almost all participants (SMS: 97\%, online-feedback: 94\%). Room for improvement was indicated particularly concerning the tailoring of the SMS messages. While nearly half of the participants $(50 \%)$ rated the online feedback as individually tailored, only $34 \%$ indicated that they perceived the SMS messages as individually tailored.

The results concerning the initial effectiveness of this program derived from a pre-post investigation were promising. The data revealed a statistically significant decrease in the percentage of persons with at least one RSOD occasion in the last month from baseline assessment (76\%) to follow-up assessment (68\%), as well as a statistically significant decrease in the percentage of persons with more than two RSOD occasions in the last month (from $48 \%$ to $41 \%$ ). Furthermore, statistically significant decreases in the percentages of persons with alcohol-related problems and in the mean number of standard drinks per week were observed. These positive changes could not be observed in persons not participating in the program.

Overall, the study showed a high acceptance and promising effectiveness of this interventional approach, combining text messaging- and web-feedback. However, the lack of a control group that was derived on the basis of random assignment as well as the short-term follow-up assessment do not allow clear conclusions to be drawn on its effectiveness. Furthermore, the combination of web-feedback and text messages does not allow conclusions to be drawn on the unique contribution of the text message-based part of the intervention.

\section{Studies on programs for smoking cessation}

Until August 2013, two published studies on text messaging-based programs for enhancing smoking

Table I Sample text messages of the program Alk-Check for different risk groups and content categories

\begin{tabular}{|c|c|c|}
\hline Risk group & Content category & Text message \\
\hline Non-risk & Drinking and body weight/fitness & $\begin{array}{l}\text { Hi Peter. Alcohol is rich in calories, slows down the body's burning of fat } \\
\text { and increases one's appetite. In short: drinking alcohol regularly makes you } \\
\text { overweight in the long term. It's great that you don't drink alcohol at all! }\end{array}$ \\
\hline Non-risk & Resisting peer pressure & $\begin{array}{l}\text { Hi Sarah. You are not just a follower who drinks alcohol to fit in. Awesome! This } \\
\text { shows strength of character and can even impress others. Only do what you } \\
\text { think is right. }\end{array}$ \\
\hline Low-risk & Importance of reducing alcohol consumption & $\begin{array}{l}\text { Hi. You would like to drink less alcohol. That's a smart decision for you! If you } \\
\text { consume less alcohol, you will feel better and have more energy the next day. }\end{array}$ \\
\hline Low-risk & Alcohol-related problems & $\begin{array}{l}\text { Hello Lucy, due to consumption of alcohol, you've had problems with your } \\
\text { parents. That's not necessary! Keep in mind that you can avoid these problems } \\
\text { by drinking less or no alcohol at all! }\end{array}$ \\
\hline High-risk & Local outpatient services for alcohol counseling & $\begin{array}{l}\text { Hi Robin. Are you concerned about your own alcohol intake or that of a friend? } \\
\text { Talking to someone about it can be really helpful. The website www.alcocheck.ch } \\
\text { can offer you support. Write an e-mail to info@alcocheck.ch or call } 04344477 .\end{array}$ \\
\hline
\end{tabular}


cessation in young people were available. The study testing the program Stop My Smoking USA was conducted in the United States in 2011/12 $2^{39}$ and the study testing the program SMS-COACH was conducted in Switzerland between 2011 and 2013. ${ }^{40}$

\section{Stop My Smoking (SMS) USA}

A pilot randomized controlled trial was conducted to test the initial efficacy of this program in young adults. ${ }^{39}$ One hundred and sixty-four daily smokers, aged 18-25 years who were seriously thinking about quitting and recruited via online advertisement, were either randomized to the 6-week intervention program or a control group. Intervention content was tailored upon the participant's stage within the quitting process. Participants of the intervention group received four messages per day during the pre-quit stage which lasted for 2 weeks; in the quit stage, they received four to nine text messages per day. The pre-quit messages aimed at encouraging smokers to clarify reasons for quitting and to understand their smoking patterns. Messages sent after the quit day addressed difficulties and discomforts associated with quitting and motivated the participants to use coping strategies. At post-quit day 2 and 7, program participants received a text message which assessed their smoking status. Participants who relapsed received two messages per day encouraging them to try quitting again at a later time. Furthermore, participants could receive text messaging support by another program participant (Text Buddy) and they could request immediate text messages helping them through a craving (Text Crave). Additional information on smoking cessation, technical support, and a discussion forum were provided on the project website.

Fifty-one percent of the program participants contacted their Text Buddy at least once during the program and 34\% of the participants used the automated support system Text Crave.

Findings concerning the initial program efficacy showed that the intervention significantly affected self-reported quitting rates at 4 weeks (intervention group: 39\%, control group: $21 \%$ ), but not at 3 months post-quit (intervention group: $40 \%$, control group: $30 \%$ ); however, the study was not adequately powered to detect differences in quit rates between the study groups at follow-up.

Overall, the study shows short-term efficacy of the smoking cessation program but does not allow conclusions to be drawn on its longer-term efficacy. Due to additional web-resources, the unique contribution of the text messages could not be assessed.

\section{SMS-COACH}

A cluster-randomized controlled trial, using a school class as a randomization unit, was conducted to test the efficacy of the SMS-COACH program compared to an assessment only control group. ${ }^{40}$ Students who smoked were proactively recruited via online screening in vocational school classes. Text messages, tailored to demographic and smoking-related variables, were sent to the participants of the intervention group over a period of 3 months.

The intervention program consisted of a) an online assessment of individual smoking behavior and attitudes towards smoking cessation, b) a weekly SMS-assessment of smokingrelated target behaviors, c) two weekly feedback messages tailored to the data of the online and SMS-assessments, and d) an integrated quit-day preparation and relapse-prevention program.

Within the online assessment, participants of the intervention group received online questions assessing outcome expectancies of smoking cessation, situations, or circumstances in which craving for cigarettes usually occurs and alternative strategies to handle these craving situations.

During the 3-month intervention period, participants received one text message per week to assess smokingrelated target behaviors. The equivalent of $€ 0.80$ was offered as reimbursement for each text message response. For all participants, the stage of change combining smoking status and intention to quit according to the Health Action Process Approach (HAPA) ${ }^{41}$ was assessed during even weeks. During odd weeks, the number of cigarettes smoked per day or week in smokers in the preintentional stages was assessed. Smokers in the intention or action stage were asked whether they applied individually chosen strategies to cope with craving situations assessed at baseline (eg, "Did you apply the following strategy recently? When I am at a party, I distract myself from smoking by dancing.").

The feedback messages were tailored to the HAPA stages and addressed: a) the risks of smoking, b) the monetary costs of smoking, c) the social norms of smoking, d) outcome expectancies, e) motivation to reduce the number of cigarettes smoked, f) social support for smoking cessation, g) strategies to cope with craving situations, h) tips for preparing for smoking cessation, and i) reward for staying abstinent. On the second level, the feedback messages were tailored according to the individual information provided at the baseline assessment as well as through the weekly SMS assessments. Sample text messages are displayed in Table 2.

Persons in the preparation and action stage had the possibility to additionally participate in an integrated program 
Table 2 Sample text messages of the program SMS-COACH

\begin{tabular}{|c|c|c|}
\hline HAPA stage & Content category & Exemplary text message \\
\hline \multirow[t]{3}{*}{ Preintentional stage } & Social norms & $\begin{array}{l}\text { Hey Mika. Did you know, not smoking is in! A survey from the University of Zurich } \\
\text { found that among 16-to-17-year old female adolescents, only II\% still smoke } \\
\text { cigarettes daily. }\end{array}$ \\
\hline & Outcome expectancies & $\begin{array}{l}\text { Hello Mika. You have the opinion, that after having stopped smoking you will be able } \\
\text { to breathe deeply more easily again. That's totally correct! Already after the first } \\
\text { weeks you are going to notice strong changes: you will be able to breathe more freely, } \\
\text { will be fitter at sports and you will be less susceptible to diseases. }\end{array}$ \\
\hline & Monetary costs of smoking & $\begin{array}{l}\text { You smoke approximately } 8 \text { cigarettes less in comparison to the beginning of the } \\
\text { program SMS-COACH. Thus, you save approximately } 70 \text { Swiss francs per month. }\end{array}$ \\
\hline \multirow[t]{2}{*}{ Intentional stage } & Social support for smoking cessation & $\begin{array}{l}\text { There are forums online in which smokers and ex-smokers exchange their } \\
\text { experiences on smoking cessation. Have a look at www.stop-tabac.ch. }\end{array}$ \\
\hline & Preparing smoking cessation & $\begin{array}{l}\text { Hi Peter. Maybe you can avoid smoking cigarettes in situations in which you usually } \\
\text { smoke by keeping yourself busy. For example, when having a break or waiting for the } \\
\text { bus it can be extremely helpful to have a chewing gum or write an SMS. }\end{array}$ \\
\hline \multirow[t]{2}{*}{ Action stage } & Reward for staying abstinent & $\begin{array}{l}\text { You can be proud of yourself to not smoke anymore. Reward yourself by buying } \\
\text { something that you have desired for a long time. }\end{array}$ \\
\hline & Coping with craving situations & $\begin{array}{l}\text { Great job, Vince: journals or a book can help you to bridge time when waiting. If there } \\
\text { is a moment in which you have nothing readily to hand, you can also distract yourself } \\
\text { by using your cell phone for calling somebody or sending a text message to someone. }\end{array}$ \\
\hline
\end{tabular}

Abbreviation: HAPA, Health Action Process Approach.

for quit-day preparation and relapse-prevention. After entering a scheduled quit date, the program provided up to two daily text messages to prepare for the quit day and to prevent relapse afterwards.

The proactive invitation for program participation allowed reaching three out of four smoking students for participation in the program SMS-COACH. Out of 1,012 smokers who met the inclusion criteria for study participation (daily or occasional smoking and ownership of a mobile phone), 755 persons (75\%) participated in the study. During the program, which lasted for 3 months, $2 \%$ of the participants in the intervention group unsubscribed from the program. The mean number of replies to the 11 weekly SMS assessments was 6.5 (standard deviation $=3.7$ ). No reply was sent by $9 \%$ of the participants; all 11 replies were sent by $15 \%$ of the participants.

Ninety-four percent of the program participants indicated that they regularly read the SMS messages. Of these, 75\% indicated that they "read the SMS messages thoroughly", $25 \%$ reported that they "took a short look at the feedback messages".

The 7-day smoking abstinence rate at 6-month follow-up was $12.5 \%$ in the intervention group and $9.6 \%$ in the control group. This difference was not statistically significant; however, the decrease in the mean number of cigarettes smoked per day from baseline to follow-up was significantly greater in the intervention group than in the control group.

Overall, the study demonstrated the potential of a text messaging-based intervention to reach a high proportion of young smokers with predominantly lower educational levels and resulted in statistically significant lower cigarette consumption. However, no short-term effects were found according to the proportion of participants who had quit. Results on the longer-term efficacy of the intervention are not available yet.

\section{Methodological quality of studies}

Criteria for the methodological quality of the four included studies are presented in Table 3. The major limitations of all these studies were that the main outcome measures were not externally validated (eg, by biochemical validation) and that no longer-term follow-up assessments beyond 6 months were conducted. Only two studies ${ }^{38,40}$ had adequate sample sizes which allowed detecting small-to-medium effect sizes.

\section{Discussion and future perspectives}

In comparison to studies testing the appropriateness and efficacy of Internet programs for reducing alcohol and tobacco use in young people, studies addressing text message-based interventions are relatively rare. ${ }^{30}$ This narrative review revealed two studies addressing alcohol use and two studies addressing smoking cessation.

All studies described tested fully-automated, text message-based interventions. The interventions showed a high feasibility and thus high economic attractiveness. Furthermore, the programs showed high retention rates. However, payments or reimbursement for active participation, like responding to regular text message assessments, 
Table 3 Methodological quality of the studies

\begin{tabular}{|c|c|c|c|c|c|c|c|}
\hline Study & Substance & Study design & Sample size & $\begin{array}{l}\text { Validation of } \\
\text { main outcome }\end{array}$ & $\begin{array}{l}\text { Final } \\
\text { follow-up }\end{array}$ & $\begin{array}{l}\text { Lost to final } \\
\text { follow-up }\end{array}$ & $\begin{array}{l}\text { Intention-to- } \\
\text { treat analyses }\end{array}$ \\
\hline Suffoletto et $\mathrm{al}^{37}$ & Alcohol & RCT & $\begin{array}{l}n=45 \text { (IG: I5, AO: } \\
n=15, C G: ~ I 5)\end{array}$ & No & 3 months & $\begin{array}{l}\text { IG: } 6.7 \% \\
\text { AO: } 20.0 \% \\
\text { CG: } 13.3 \%\end{array}$ & No \\
\hline Haug et $\mathrm{al}^{38}$ & Alcohol & Pre-post-study & $n=364$ & No & 3 months & $23.1 \%$ & Yes \\
\hline Ybarra et al $^{39}$ & Tobacco & $\mathrm{RCT}$ & $\mathrm{n}=164$ (IG: I0I, CG: 63) & No & 3 months & IG: $10.9 \%$ & Yes \\
\hline Haug et $\mathrm{al}^{40}$ & Tobacco & Cluster RCT & $\mathrm{n}=755$ (IG: 372, CG: 383) & No & 6 months & $\begin{array}{l}\text { IG: } 22.8 \% \\
\text { CG: } 29.0 \%\end{array}$ & Yes \\
\hline
\end{tabular}

Abbreviations: RCT, randomized controlled trial; IG, intervention group; AO, assessment only group; CG, control group.

might have also contributed to this result. The studies testing the programs Alk-Check and SMS-COACH, in which program participants were recruited proactively within school classes, showed high participation rates compared to traditional intervention approaches. ${ }^{38,40}$ The available results on the short-term efficacy of the programs are promising. However, further adequately powered randomized studies are needed to confirm these initial results and to test the longer-term efficacy of text message-based interventions for the reduction of tobacco and alcohol use in young people. Furthermore, the studies focusing on smoking cessation would especially benefit from external validation of their main outcome measures eg, by cotinine measures.

One major difficulty of all technology-based interventions lies in rapid technological development in contrast to the time-consuming process of gathering empirical evidence. Typically, the process of developing a program, pilot-testing the program, and conducting a randomized trial and replication nearly takes a decade. Although mobile phone text messaging is still one of the most commonly used mobile phone applications in young people, ${ }^{32}$ other applications like WhatsApp, which allows users to send texts, pictures, or video messages via smartphones are increasingly utilized and might replace traditional mobile phone text messaging more and more within the next years. Nevertheless, systematic evaluations of technology-delivered programs are indispensable and provide valuable information on whether an intervention approach should be pursued. Future mobile phone text messaging-based programs might also benefit from the increasing dissemination of smartphones; web links to video channels like YouTube, to social networks, or to websites which provide additional information could be embedded easily within mobile phone text messages.

Mobile phones have become an integral part of young people's lives within the last decade and mobile phone-based interventions have enormous potential for individualized interventions to reduce tobacco and alcohol use, which could be provided on the population level. We hope that this potential will be recognized within the next few years and will result in increased research on this topic.

\section{Disclosure}

The author reports no conflicts of interest in this work.

\section{References}

1. Lim SS, Vos T, Flaxman AD, et al. A comparative risk assessment of burden of disease and injury attributable to 67 risk factors and risk factor clusters in 21 regions, 1990-2010: a systematic analysis for the Global Burden of Disease Study 2010. Lancet. 2012;380(9859): 2224-2260.

2. Rehm J, Taylor B, Room R. Global burden of disease from alcohol, illicit drugs and tobacco. Drug Alcohol Rev. 2006;25(6):503-513.

3. Anderson P, Baumberg B. Alcohol in Europe. A Public Health Perspective. A Report for the European Commission. London: Institute of Alcohol Studies; 2006. Available from: http://ec.europa.eu/health/ ph_determinants/life_style/alcohol/documents/alcohol_europe.pdf. Accessed September 25, 2013.

4. Gmel G, Bissery A, Gammeter R, et al. Alcohol-attributable injuries in admissions to a swiss emergency room - an analysis of the link between volume of drinking, drinking patterns, and preattendance drinking. Alcohol: Clin Exp Res. 2006;30(3):501-509.

5. Hingson RW, Edwards EM, Heeren T, Rosenbloom D. Age of drinking onset and injuries, motor vehicle crashes, and physical fights after drinking and when not drinking. Alcohol Clin Exp Res. 2009;33(5): 783-790.

6. Hingson RW, Heeren T, Edwards EM. Age at drinking onset, alcohol dependence, and their relation to drug use and dependence, driving under the influence of drugs, and motor-vehicle crash involvement because of drugs. J Stud Alcohol Drugs. 2008;69(2):192-201.

7. Hingson RW, Heeren T, Zakocs RC, Kopstein A, Wechsler H. Magnitude of alcohol-related mortality and morbidity among US college students ages 18-24. J Stud Alcohol. 2002;63(2):136-144.

8. British Medical Association (BMA). Alcohol: Guidelines on Sensible Drinking. London, UK: British Medical Association; 1995.

9. Gmel G, Kuntsche E, Rehm J. Risky single-occasion drinking: bingeing is not bingeing. Addiction. 2011;106(6):1037-1045.

10. Kuntsche E, Rehm J, Gmel G. Characteristics of binge drinkers in Europe. Soc Sci Med. 2004;59(1):113-127.

11. Hibell B, Guttormsson U, Ahlström S, et al. The 2011 ESPAD Report. Substance Use Among Students in 36 European Countries. Stockholm, Sweden: The Swedish Council for Information on Alcohol and other Drugs (CAN) 2012.

12. Chassin L, Presson CC, Sherman SJ, Edwards DA. The natural history of cigarette smoking: predicting young-adult smoking outcomes from adolescent smoking patterns. Health Psychol. 1990;9(6):701-716. 
13. Dwyer JB, McQuown SC, Leslie FM. The dynamic effects of nicotine on the developing brain. Pharmacol Ther. 2009;122(2):125-139.

14. Haug S, Schaub MP, Salis Gross C, John U, Meyer C. Predictors of hazardous drinking, tobacco smoking and physical inactivity in vocational school students. BMC Public Health. 2013;13:475.

15. Bewick BM, Trusler K, Barkham M, Hill AJ, Cahill J, Mulhern B. The effectiveness of web-based interventions designed to decrease alcohol consumption-a systematic review. Prev Med. 2008;47(1):17-26.

16. Miller JH, Moyers T. Motivational interviewing in substance abuse applications for occupational medicine. Occup Med. 2002;17(1): $51-65$.

17. Perkins HW. The Social Norms Approach to Preventing School and College Age Substance Abuse: A Handbook for Educators, Counselors, and Clinicians. 1st ed. San Francisco: Jossey-Bass; 2003.

18. Carey KB, Scott-Sheldon LA, Carey MP, DeMartini KS. Individuallevel interventions to reduce college student drinking: a meta-analytic review. Addict Behav. 2007;32(11):2469-2494.

19. Grimshaw GM, Stanton A. Tobacco cessation interventions for young people. Cochrane Database Syst Rev. 2006;(4):CD003289.

20. Sussman S, Sun P. Youth tobacco use cessation: 2008 update. Tob Induc Dis. 2009;5:3.

21. Hollis JF, Polen MR, Whitlock EP, et al. Teen reach: outcomes from a randomized, controlled trial of a tobacco reduction program for teens seen in primary medical care. Pediatrics. 2005;115(4):981-989.

22. Backinger CL, Michaels CN, Jefferson AM, Fagan P, Hurd AL, Grana R. Factors associated with recruitment and retention of youth into smoking cessation intervention studies - a review of the literature. Health Educ Res. 2008;23(2):359-368.

23. Glasgow RE, Klesges LM, Dzewaltowski DA, Estabrooks PA, Vogt TM. Evaluating the impact of health promotion programs: using the RE-AIM framework to form summary measures for decision making involving complex issues. Health Educ Res. 2006;21(5):688-694.

24. Pbert L, Flint AJ, Fletcher KE, Young MH, Druker S, DiFranza JR Effect of a pediatric practice-based smoking prevention and cessation intervention for adolescents: a randomized, controlled trial. Pediatrics. 2008;121(4):e738-e747.

25. Peterson AV Jr, Kealey KA, Mann SL, Marek PM, Ludman EJ, Liu J, et al. Group-randomized trial of a proactive, personalized telephone counseling intervention for adolescent smoking cessation. J Natl Cancer Inst. 2009;101(20):1378-1392.

26. Walters ST, Wright JA, Shegog R. A review of computer and Internetbased interventions for smoking behavior. Addict Behav. 2006;31(2): 264-277.

27. Noar SM, Benac CN, Harris MS. Does tailoring matter? Meta-analytic review of tailored print health behavior change interventions. Psychol Bull. 2007;133(4):673-693.
28. Chua HF, Ho SS, Jasinska AJ, et al. Self-related neural response to tailored smoking-cessation messages predicts quitting. Nat Neurosci. 2011;14(4):426-427.

29. Kreuter MW, Wray RJ. Tailored and targeted health communication: strategies for enhancing information relevance. Am J Health Behav. 2003;27 Suppl 3:S227-S232.

30. Haug S, Sannemann J, Meyer C, John U. [Internet and mobile phone interventions to decrease alcohol consumption and to support smoking cessation in adolescents: a review]. Gesundheitswesen. 2012;74(3): 160-177. German.

31. Moreira MT, Smith LA, Foxcroft D. Social norms interventions to reduce alcohol misuse in university or college students. Cochrane Database Syst Rev. 2009;(3):CD006748.

32. Willemse I, Waller G, Süss D, Genner S, Huber A-L. [JAMES: Youth, Activity, Media - Data for Switzerland]. Zürich: Zürcher Hochschule für angewandte Wissenschaften; 2012. German.

33. Whittaker R, McRobbie H, Bullen C, Borland R, Rodgers A, Gu Y. Mobile phone-based interventions for smoking cessation. Cochrane Database Syst Rev. 2012;11:CD006611.

34. Fjeldsoe BS, Marshall AL, Miller YD. Behavior change interventions delivered by mobile telephone short-message service. Am J Prev Med. 2009;36(2):165-173.

35. Free C, Knight R, Robertson S, et al. Smoking cessation support delivered via mobile phone text messaging (txt2 stop): a single-blind, randomised trial. Lancet. 2011;378(9785):49-55.

36. Kuntsche E, Robert B. Short message service(SMS) technology in alcohol research - a feasibility study. Alcohol Alcohol. 2009;44(4):423-428.

37. Suffoletto B, Callaway C, Kristan J, Kraemer K, Clark DB. Textmessage-based drinking assessments and brief interventions for young adults discharged from the emergency department. Alcohol Clin Exp Res. 2012;36(3):552-560.

38. Haug S, Schaub MP, Venzin V, et al. A pre-post study on the appropriateness and effectiveness of a web- and text messaging-based intervention to reduce problem drinking in emerging adults. $J$ Med Internet Res. 2013;15(9):e196.

39. Ybarra ML, Holtrop JS, Prescott TL, Rahbar MH, Strong D. Pilot RCT results of stop my smoking USA: a text messaging-based smoking cessation program for young adults. Nicotine Tob Res. 2013;15(8):1388-1399.

40. Haug S, Schaub MP, Venzin V, Meyer C, John U. Efficacy of a text message-based smoking cessation intervention for young people: a cluster randomized controlled trial. J Med Internet Res. 2013;15(8):e171.

41. Schwarzer R. Modeling health behavior change: how to predict and modify the adoption and maintenance of health behaviors. Appl Psychol Int Rev. 2008;57(1):1-29.
Smart Homecare Technology and TeleHealth

\section{Publish your work in this journal}

Smart Homecare Technology and TeleHealth is an international, peer-reviewed, open access online journal publishing original research, reviews, editorials and commentaries on the application of technology to support people and patients at home and in assisted living centers to optimize healthcare and management resources. Specific topics in the journal include: Development and application of

\section{Dovepress}

devices within the home and embedded in appliances; Healthcare provider communication and education tools; and drug ordering and adherence. The manuscript management system is completely online and includes a very quick and fair peer-review system, which is all easy to use. Visit http://www.dovepress.com/ testimonials.php to read real quotes from published authors. 